\title{
Evaluation of High-Speed Track Quality Using Dynamic Simulation of Vehicle-Track Interaction
}

\author{
D. Liu, B. Lechner, S. Freudenstein \\ Chair and Institute of Road, Railway and Airfield Construction, Technische Universitaet Muenchen, Munich, Germany \\ Email:duo.liu.deu@gmail.com,stephan.freundenstein@vwb.bv.tum.de
}

Received 20 September 2015; accepted 4 January 2016; published 7 January 2016

Copyright (C) 2016 by authors and Scientific Research Publishing Inc.

This work is licensed under the Creative Commons Attribution International License (CC BY).

http://creativecommons.org/licenses/by/4.0/

(c) (i) Open Access

\begin{abstract}
Track quality is a determinant factor for evaluating the overall performance of vehicle track interaction with respect to safety, ride quality and maintenance. Important parameters specifying the general quality of the track include track geometry (undamped) and track stiffness (damped), which can be evaluated by measurements taken along with track sections. A new co-simulation model based on Finite Element Method (FEM) and Multi Body Simulation (MBS) is built for the detailed description of track quality and its contribution to vehicle track interaction without simplifying the track structure as interconnected single elements. The simulation models and tools have been validated with the help of measured track geometry, track stiffness and dynamic wheel rail forces along the track sections of high speed lines. A comparative study between high speed lines using conventional ballasted track and ballastless track showed a significantly better quality in ballastless track sections. The dynamic forces which were determined by simulations and verified by measurements along the ballastless track section were comparatively less than the specified limits by German regulations for ballastless track design. Lower levels of dynamic forces can be utilized for optimization of track design and installation procedures with respect to lower initial costs.
\end{abstract}

\section{Keywords}

Dynamic Wheel Load, Vehicle Track Interaction, FEM MBS Co-Simulation, Ballastless Track Design

\section{Importance of High-Speed Track Quality}

The term "track quality" describes the conformance of actual alignment of wheel-rail contact point of the loaded

How to cite this paper: Liu, D., Lechner, B. and Freudenstein, S. (2016) Evaluation of High-Speed Track Quality Using Dynamic Simulation of Vehicle-Track Interaction. Journal of Transportation Technologies, 6, 9-14.

http://dx.doi.org/10.4236/jtts.2016.61002 
rail to the designed rail alignment. The actual track quality is dependent on construction work procedures or degree to which the track is properly maintained. In combination with the actual quality level of rail vehicles and speed, the track quality contributes to the overall ride quality (passenger's comfort) and safety level.

This research is focusing on the evaluation of track quality with respect to possible improvements of track technology. Consequently, additional effects which are dependent on vehicle maintenance procedures and requirements are not studied. Most of the research based on vehicle-track interaction focuses only on the vehicle using a rigid track or considers the track structure as singular and discrete vibration absorber via wheel-rail contact mechanisms. These methods and their respective results can be observed in [1]-[4]. Dietz et al. [5] describes a co-simulation model for a vehicle passing an elastic bridge.

The level of additional dynamic forces activated along a conventional ballasted track section can be used as an indicator for maintenance needs (tamping intervals). There is also an interaction between the track performance (in terms of stiffness and damping) and track quality (in terms of irregularity). The appearance of track irregularity along a new track shows stochastic distributions which are highly dependent on the initial condition of track and the traffic load. When there are certain track irregularities, the deterioration of track quality (conventional ballasted track) according to the traffic load is relative to the overall track stiffness. Track stiffness in turn is one of the most determinant factors from the track side on the level of excitation load activated. Hence, it is intuitive that higher track deterioration rate should appear in the location where higher vehicle excitation load is activated.

In the past decades, a number of ballastless track systems have been developed for high-speed lines to offer "maintenance free" tracks which provide a constant high quality. The contribution of the track technology part of the railway system is to minimize the additional dynamic forces generated at the wheel-rail interface and to improve the ballastless track design. Dynamic forces are decisive for the behavior of rail supporting structures (e.g. concrete slab) which is determinant to the service life (60 years according to the German regulations [6]) of ballastless track systems.

The track quality is dependent on the rail alignment (track geometry) achieved during construction and track stiffness along the track which in turn is dependent on the performance of rail supporting structures. In case of ballastless track systems, the track stiffness should be defined by stiffness of the fastening system used. Stiffness of the fastening system is affected by the quality of rail pads and the pre-stressing force of clamps or clips (the chosen ballastless track installation procedure may affect the individual clamping force of rail seats). The changes within substructure stiffness should be balanced with the help of a stiff rail supporting structure and respective transition zone design.

The contribution of sub-system (e.g. fastening systems) and sub-system configuration of ballastless tracks with respect to the dynamic vertical wheel rail forces is studied. It provides a systematic solution for the research based on vehicle track interaction by distinguishing the effects coming from track excitation (plastic, undamped) and the effects coming from track stiffness (elastic, damped). For this reason, the realistic track bed structure should be considered for simulation instead of simplifying them into interconnected single elements.

In order to achieve a dynamic behavior in the system, a vehicle-track interaction model based on both FiniteElement-Method (FEM) and the Multi-Body-Simulation (MBS) was built. These numerical procedures focus on the track foundation, quasi-static and dynamic performance of the track superstructure. The modelling of track stiffness was achieved by FEM software ANSYS [7], it was a multi-elastic model with discrete description of rail, pad, sleeper and substructure. The precision of the modelling of track stiffness is scaled to rail seat distance. After verification, this model was then imported into the vehicle model by modal representation. Vehicle and track geometry were modeled in MBS software SIMPACK [8], where a detailed wheel-rail contact mechanism (Kalker contact theory (Method "FASTSIM") [9]) was included. For this study, a modern E-locomotive with an axle load of $21.5 \mathrm{t}$ was built (parameters partially from Manchester Benchmarks [10]). The 3D track geometry in terms of "vertical", "lateral", "gauge" and "Roll" can be given, whose data are acquired by field measurement. Additional movable spring-damper pairs were created under each wheel for the calculation of the wheel-rail contact force.

\section{Determination of Actual Track Quality}

Quality of high speed tracks is regularly monitored by an infrastructure manager with the help of track recording cars or instrumented axles of regular trains to measure dynamic forces along the tracks. In order to achieve the required accuracy for this detailed study, a track based approach has been chosen to clearly separate rail geome- 
try and track stiffness effects on a "rail seat to rail seat" basis.

A High-speed ballastless track section in Germany with operational speed of $300 \mathrm{~km} / \mathrm{h}$ was examined. To exclude dynamic effects activated by the track alignment or potential discontinuities in substructure performance (e.g. differential settlements between tracks on embankment and on bridge), a test section located along a straight, horizontal open track section with homogenous substructure layout has been selected.

\subsection{Track Geometry}

The design of modern passenger coach always follows the principle that an eigen frequency of approximately 1 $\mathrm{Hz}$ should be achieved [11], which means the calm down time for single impulse could be up to 1second long. This defines the minimum wave length which should be included in the calculation of track geometry. The maximum design speed of the line is $300 \mathrm{~km} / \mathrm{h}$ (around $83 \mathrm{~m} / \mathrm{s}$ ) which gives a characteristic wave length of $83 \mathrm{~m}$. From the previous measurement experiences at the institute, the wave length must have more than 10 repeats in each measurement. Hence, a total length which is more than $830 \mathrm{~m}$ should be measured.

In track geometry, the representation of potential deviations of the rail alignment (unloaded) in vertical and lateral direction compared to design rail alignment is fixed by the ballastless track construction procedures. In this study the track geometry measurement was done by track recording trolley manufactured by the company Vogel \& Plötscher with a type series called "MessReg CLS" [12]. The measurement of vertical and lateral track geometry of this device relies on the three-point measurement principle. The absolute geometry is recalculated with the help of the Linear-Time-Invariant (LTI) system approach. The shortest wave length is defined to $0.65 \mathrm{~m}$ which is identical to the rail seat spacing. Figure 1 describes the measured vertical track geometry.

For comparison, the statistical standard deviation in a selected length of $100 \mathrm{~m}$ is attached in Table 1 . The control value specified by the DB-AG standard for ballastless tracks [6] is given as reference. This documents the limit of variation in track geometry with respect to different wave length using the representation of Power Spectral Density (PSD) curve. The quality level of the measured track fulfils the rail alignment quality level defined by [6]. The PSD curve of the measured track and AKFF guideline can be seen in Figure 2 (free factor = 1.0).

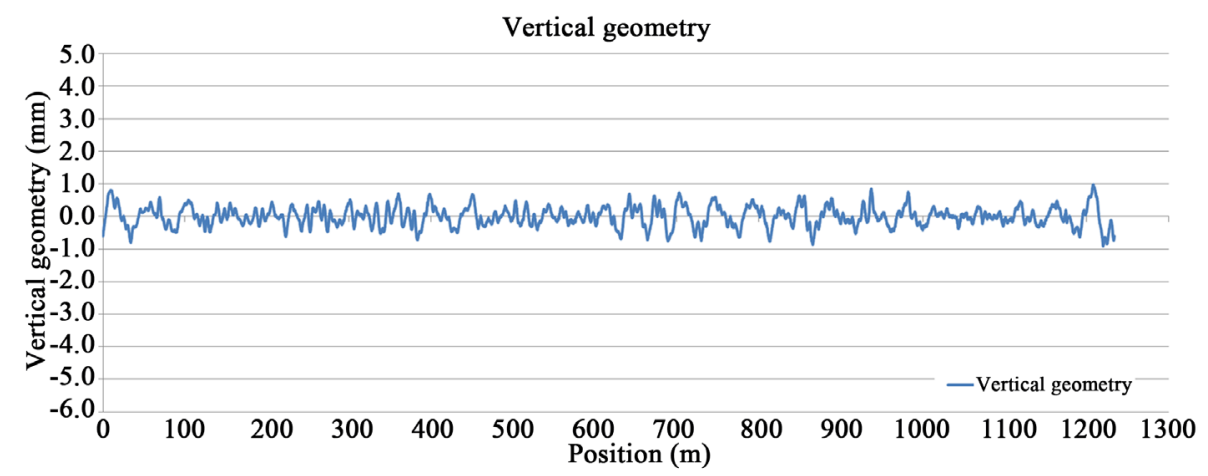

Figure 1. Measured vertical absolute track geometry.

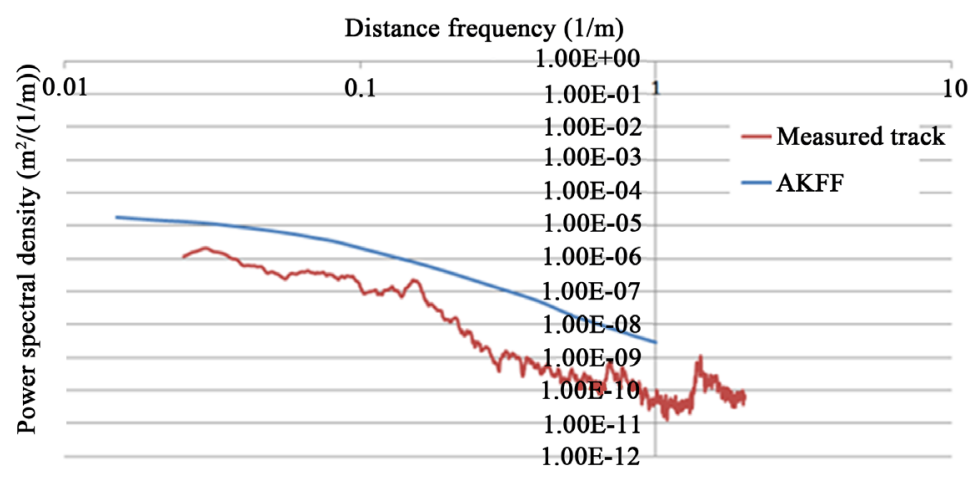

Figure 2. PSD distribution of the measured track and AKFF guideline. 
Table 1. Standard deviation of standard and measured track.

\begin{tabular}{cc}
\hline Track & Standard deviation of track geometry (100 m track) \\
\hline Measured high speed ballastless track & $0.20 \mathrm{~mm}$ \\
Limit [6] & $0.91 \mathrm{~mm}$ \\
\hline
\end{tabular}

\subsection{Track Stiffness}

The uniformity of vertical track stiffness can be checked by rail deflection measurements on certain amount of rail seats within the test section. It must be taken into account that the track stiffness determined by rail deflection at a certain point is influenced by the individual stiffness of several rail seats (fastening systems) nearby.

This measurement was done using the modified "Benkelman beam wagon" designed by the Institute of road, railway and airfield construction of Technische Universitaet Muenchen. It provides the measurement of elastic rail deflection under each rail seat. The precision of the measurement is $\pm 0.05 \mathrm{~mm}$. Figure 3 shows the measurement principle of the equipment. It can record both the maximum deflection and deflection line during the approach of the loaded wheel. In the measurement, a loco was used to push and pull the wagon at walking speed within a stop to stop distance of about $10 \mathrm{~m}$. A total number of 120 rail seats (60 continuous rail seats on each rail) were measured. The average value of the measured maximum rail deflection is $1.49 \mathrm{~mm}$ with a standard deviation of $0.07 \mathrm{~mm}$ under an activated static axle load of $20 \mathrm{t}$. This is according to the design requirement of rail deflection $1.5 \mathrm{~mm}$ activated by $20 \mathrm{t}$ axle load.

\section{Dynamic Vehicle Track Interaction-Case Study}

The track model contains both the geometry and variation of track stiffness. Here the modelling of rail pad and its pre-stressing force in the fastening system relies on 3D volume element. There is no change in the substructure of the test section and therefore the change of substructure stiffness is neglected. The Young's modulus of the rail pad is set as variable and individually adjusted based on measurement data (see track stiffness measurement). The difficulties in determination of the Young's modulus of rail pad in a rail seat element depends on the fact that the elastic deflection at each single rail seat is different and partially dependent on the Young's modulus of the pad of the neighboring rail seat element. An iteration method is setup for determination of the elasticity modulus for each segment of the ballast layer. The iteration is not only able to adjust the measured maximum rail deflection, but also the total deflection line. By using this method, a converged result can be achieved after 5 or 6 iterations. Measured samples and simulated deflection lines can be found in Figure 4.

The simulated dynamic wheel load was filtered with a low pass filter at $f=130 \mathrm{~Hz}$. This value was determined according to the train speed $(300 \mathrm{~km} / \mathrm{h})$ and the shortest wave length of measured track geometry $(0.65$ $\mathrm{m})$. Therefore, the maximum Eigen frequency of the rail structure included must be greater than $1300 \mathrm{~Hz}$ for better representation of the track side influence. For simulation under higher vehicle speed, a modal damping of $5 \%$ (inclusion of rubber rail pads) is required [13].

The dynamic load factor is an important information for a ballastless track designer which is calculated by the division of maximum induced dynamic wheel load and the static load. Table 2 documents the simulated maximum dynamic load factor for the measured track. The value for AKFF track is simulated under a virtual generated track which holds the same PSD distribution as AKFF. For further improvement of the specific ballastless track design and its installation procedure, detailed knowledge on track geometry and track stiffness effects should be analyzed separately.

It can be concluded from the simulation results that the inclusion of track stiffness is slightly improving the vehicle track interaction performance by reducing the dynamic load factor. The reason is that the reduced stiffness and high damping of the ballastless track system provided by high resilient fastening systems can partially compensate the effect of track irregularity. It can be seen that further reduction of the dynamic load factor is possible by the adjustment of track stiffness and damping properties.

The modern high speed lines induce lesser dynamic effect between vehicle and track under higher speed limit, due to an improvement in track geometry condition. The case "measured high speed ballasted track" of Table 2 represents a measured high speed ballasted track for about 1 year of operation. The dynamic loading factor of $25.2 \%$ is the best case scenario for ballasted track under that speed level. For a smoother track like in the case of 


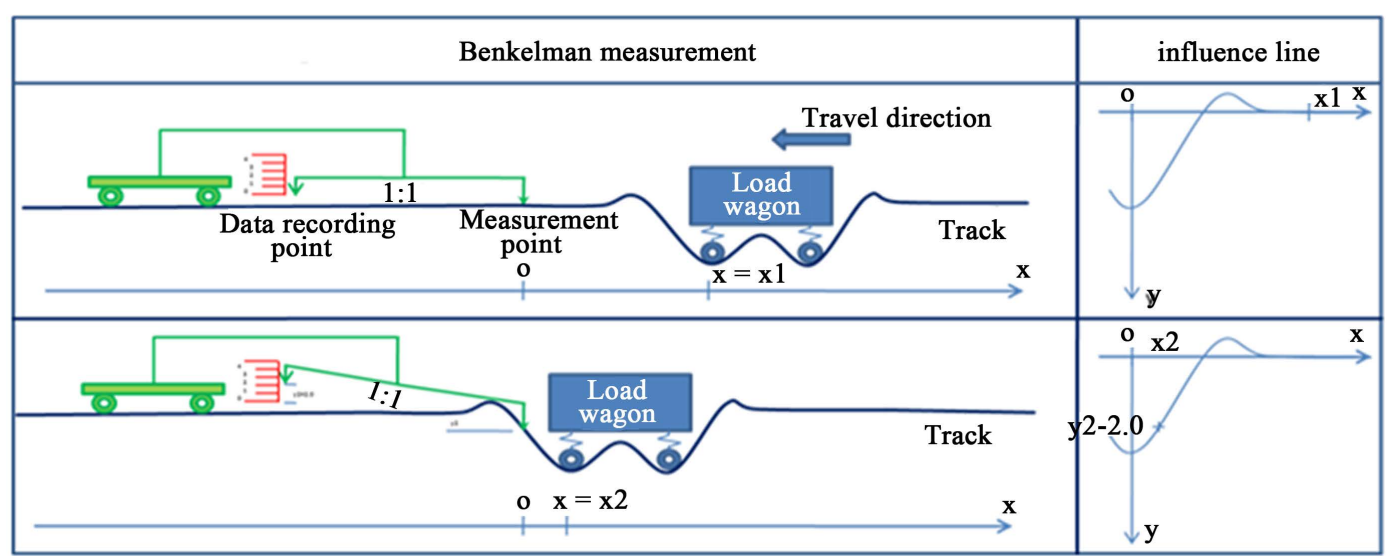

Figure 3. Modified Benkelman beam for the measurement of track elastic deflection.

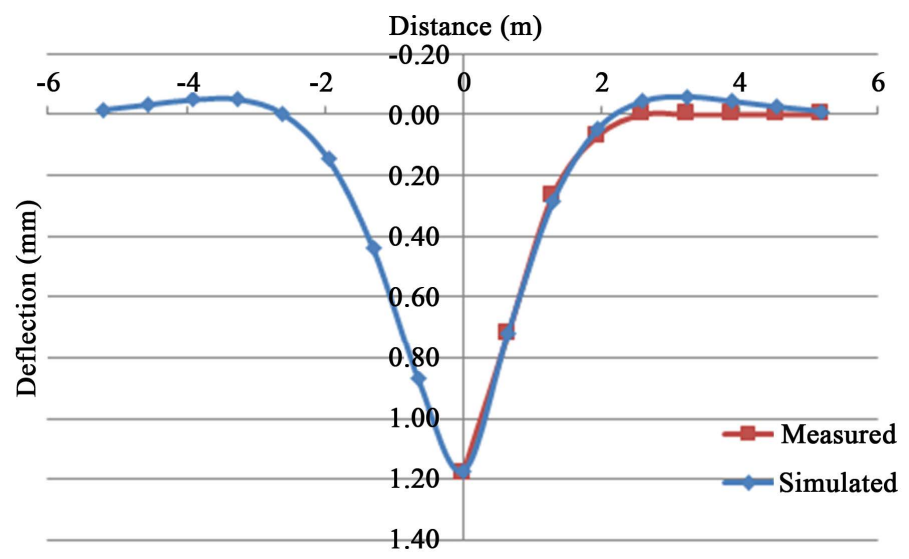

Figure 4. Measurement and simulation result after 6th iteration (max. rail seat deflection of all rail seats).

Table 2. Dynamic loading factor.

\begin{tabular}{ccc}
\hline Track & Type & Maximum Dynamic load factor (\%) \\
\hline Measured ballastless track & Only geometry & 11.4 \\
$(\mathrm{~V}=300 \mathrm{~km} / \mathrm{h})$ & Only Stiffness & 8.6 \\
& Geometry + Stiffness & 11.1 \\
Measured high speed ballasted track & Only geometry & 24.6 \\
$(\mathrm{~V}=250 \mathrm{~km} / \mathrm{h})$ & Only Stiffness & 6.3 \\
& Geometry + Stiffness & 25.2 \\
PSD reference track $[6]$ & Geometry + Stiffness & 29.5 \\
\hline
\end{tabular}

“measured ballastless track" the dynamic loading factor is only $11.1 \%$. This can be realized only under ballastless track allocation. The result clearly symbolizes the advantage of inclusion of ballastless track system for achieving better track quality.

The calculation of dynamic load in design phase normally follows the empirical approach released by German rail in 1993 [14]. For passenger trains, a dynamic load factor of 1.5 (based on a confidence level of 99.7\%) shall be taken into consideration. It is proved from the simulation models, that a smaller dynamic load factor can be applied if the track quality fulfils the minimum requirement defined by [6].

\section{Summary and Remarks}

A systematic approach is being presented in this paper. A real-time modelling is realized by using the co-simulation of FEM and MBS for understanding the track sided parameters to the overall performance of ve- 
hicle track interaction. These track sided parameters are generally defined by the term "track quality" which contains two main aspects: track geometry (undamped), and track stiffness (damped). Field side measurements on high speed ballastless track were performed and the measurement data were utilized as input. The simulation helps to enlarge the sight of understanding the distribution of dynamic wheel load. The results provide evidence that the simulation models are suitable to meet the respective requirements. The simulation of the wheel dynamic load in time sequence is now detailed to single rail seat which is more accurate in positioning than direct measurement.

It is to conclude from the simulation output that the inclusion of track stiffness will generally reduce the impact of vehicle track interaction for high speed ballastless track system, whereas for ballasted track system, the opposite consequence can be seen. This is due to the inclusion of high elastic pad in the ballastless track structure, whereas the ability of high elastic pad in maintaining their quality after longer period in operation is still unknown. In general, the vehicle track interaction performance in terms of maximum dynamic load factor is minimized in ballastless track structure compared to ballasted track structure due to better track quality. It can also be concluded from the new co-simulation model that the individual influencing parameters, like vehicle speed, track geometry and track stiffness, can be adjusted in the model easily from scenario to scenario.

\section{Acknowledgements}

This work was performed in the chair and institute of road, railway and airfield construction of Technische Universitaet Muenchen (TUM) in Munich, Germany (see http://www.vwb.bgu.tum.de/en/home/). The research is fully supported by the Karl-Vossloh funding (Project S047/10021/2011) since January 2012. The team would like to thank the support of German railway (DB) for provision of the measurement section.

\section{References}

[1] Knothe, K.L. and Grassie, S.L. (1993) Modelling of railway Track and Vehicle/Track Interaction at High Frequencies. Vehicle System Dynamics, 22, 209-262. http://dx.doi.org/10.1080/00423119308969027

[2] Wickens, A.H. (2003) Fundamentals of Rail Vehicle Dynamics: Guidance and Stability. Swets \& Zeitlinger Publishers, The Netherlands. http://dx.doi.org/10.1201/9780203970997

[3] Zhai, W.M., Wang, K.Y. and Cai, C.B. (2009) Fundamentals of Vehicle-Track Coupled Dynamics. Vehicle System Dynamics, 47, 1349-1376. http://dx.doi.org/10.1080/00423110802621561

[4] Kassa, E. and Nielsen, J.C.O. (2008) Dynamic Interaction between Train and Railway Turnout: Full-Scale Field Test and Validation of Simulation Models. Vehicle System Dynamics, 46, 521-534. http://dx.doi.org/10.1080/00423110801993144

[5] Dietz, S., Hippmann, G. and Schupp, G. (2002) Interaction of Vehicles and Flexible Tracks by Co-Simulation of Multibody Vehicle Systems and Finite Element Track Models. Vehicle System Dynamics, 37, 372-384.

[6] DB Netz AG/DB Systemtechnik (2002) Anforderungskatalog zum Bau der Festen Fahrbahn-4. Überarbeitete Auflage-Stand 01.08.2002.

[7] ANSYS, Inc. (1999) Theory Reference. ANSYS Release 5.6, 11th Edition.

[8] Intec GmbH (2008) Simpack Reference Guide. Simpack Release 8.9, Wessling, Germany.

[9] Kalker, J.J. (1982) A Fast Algorithm for the Simplified Theory of Rolling Contact. Vehicle System Dynamics, 11, 1-13. http://dx.doi.org/10.1080/00423118208968684

[10] Iwnicki, S. (1998) The Manchester Benchmarks for Rail Vehicle Simulation. Rail Technology Unit, Manchester Metropolitan University, Manchester, United Kingdom.

[11] Weidemann, C. (2003) Air-Springs in Simpack. SIMPACK News, Wessling, Germany.

[12] Vogel \& Plötscher (2010) Production Catalogue. MessReg CLS., Breisach, Germany. http://www.vogelundploetscher.de

[13] SIMPACK AG (2011) Flexible Bodies Tutorial I. Simpack Documentation Release 9.7, Wessling, Germany, 82.

[14] Detusche Bundesbahn (1993) Oberbauberechnung. Munich, Germany. (In German) 